\title{
Library Computer Workstations for Inclusive College Student Populations
}

\author{
Brady C. Cross, Tri-County Technical College, USA
}

\begin{abstract}
Most academic library computer workstations comply with basic accessibility guidelines; however, very few are designed for all users. Technology that enables differently-abled individuals to access library materials exists. The research within this article explores the reasons why academic libraries may or may not choose to incorporate these technologies into their facilities. The author created a "Universal Access Workstation" (UAW), a workstation that incorporates assistive and adaptive technology, which enables equitable access to information for patrons with and without disabilities. This study addresses the lack of UAW technology in academic libraries when inclusivity is not only broadly accepted, but enthusiastically embraced by institutions of higher learning. The literature review addresses Universal Design and the UAW, and how effectively librarians have progressed from the Americans with Disabilities Act of 1991 (ADA) as a minimal standard to Universal Design and Universal Design for Learning (UDL) as a framework. Empirical evidence was collected in an online survey which included questions that addressed academic librarians' attitudes and opinions regarding the UAW and Universal Design in academic libraries. The study reinforces that the social construct of disability is determined, in part, by the facilities which we design. The article also reveals evidence which indicates that there may be a positive trend toward acceptance of Universal Design in library technology, acceptance which should lead a paradigm shift away from the social construct of disability. This research concludes that libraries incorporating a UAW into their facility promote equitable access to information for all users and enable everyone to participate in the learning process.
\end{abstract}

Keywords: accessibility; assistive technology; disability; social construction; Universal Design

Publication Type: research article

\section{Introduction}

$\mathrm{T}$ he modern college student population includes persons with varying physical and mental abilities, but not all academic libraries feature computer workstations that are fully accessible or universally designed. The Universal Access Workstation (UAW) features all the components of a standard workstation; however, it includes software, hardware, and furniture with enhanced and additional assistive and adaptive technology to allow persons with disabilities the opportunity to increase their access to information. According to Robert Taylor (1987), the value of information is only as good as the user's ability to access it. This theory, referred to as Taylor's Information Use Environments (Taylor's IUE), places the facility and equipment, or user environment, in judgment as it requires a value of how information delivery is to be assessed (Taylor, 1987). The UAW helps demarginalize those with disabilities because it features this specialized equipment. Some of the specialized software associated with the UAW includes

The International Journal of Information, Diversity, \& Inclusion, 4(1), 2020

ISSN 2574-3430, jps.library.utoronto.ca/index.php/ijidi

DOI: $10.33137 /$ ijidi.v4i1.32340 
screen readers, document readers (Optical Character Recognition, or OCR, that converts an image to text), document magnifiers, voice capture, adaptive internet browser extensions, hands-free input device software, and accessibility functions enabled in the operating system. Although the UAW cannot resolve all barriers such as inaccessible databases and/or websites, it does ensure access to print materials and electronic documents that lack OCR text.

Examples of UAW hardware include large screen monitors (preferably in an all-in-one terminal), a document camera, noise-cancelling microphone and headphones, high-visibility keyboard and mouse, a hands-free input system (pointing device replaces mouse), an adaptive trackball mouse, and switches (mouse click buttons used with trackball mouse). Furniture examples include an ergonomic chair, footrest, wrist rest, and a push-button adjustable height worktable (desk). These features ensure that patrons are able to use the computer without barriers in addition to a degree of comfort not associated with typical computer workstations. The adjustable height table has a surface similar in size and style to other library furniture. The difference is that the base is adjustable in height. The UAW table and the all-in-one monitor blends in with other library computer workstations, making the high-visibility keyboard, document camera, and adaptive trackball mouse the only stand-out features.

Academic libraries typically have computer workstations that feature a desktop computer on a fixed-height table with a standard keyboard and mouse as input devices. These average workstations comply with the 2010 Americans with Disabilities Act (ADA) Standards for Accessible Design guidelines and are an adequate design for the majority of the college student population. However, these workstations can exclude patrons with visual impairments, deafness, and/or mobility issues. Should academic libraries incorporate one or more UAWs to ensure their physically or cognitively varied student population has equitable access to information? Does promotion of an inclusive environment justify the extra expense of the UAW's associated technology features? This article explores how academic libraries featuring a UAW ensure that information is accessible to physically or cognitively varied students. The empirical research survey addresses the questions above and gauges librarian attitudes toward fostering an inclusive environment.

Although the research problem, questions, and solutions in this paper could be applied in any type of library, one of the goals of this research is to show that the UAW supports the Universal Design for Learning (UDL) approach used in the university setting, and that all students need equitable access to information to achieve a positive learning outcome. The UDL approach is an adaptation of the Principles of Universal Design (NC State University, 1997), which ensures equitable access to learning materials and provision of a variety of teaching methods. This goal is in addition to the provision of access to information for personal reasons outside of the classroom.

This article begins with an analysis of the social construction of disability and the differentlyabled in libraries. The literature review addresses Universal Design, UDL, and the UAW, and how effectively librarians have progressed from the ADA as a standard to Universal Design as a framework. The methodology explains how survey research was utilized to design the empirical research survey. The discussion further analyzes the data gained from the survey and the results show that libraries featuring UAW technology rectify earlier technological accessibility challenges by use of the Principles of Universal Design (NC State University, 1997).

The International Journal of Information, Diversity, \& Inclusion, 4(1), 2020

ISSN 2574-3430, jps.library.utoronto.ca/index.php/ijidi/index

DOI: $10.33137 /$ ijidi.v4i1.32340 


\section{Social Construction and the Differently-abled}

Modern library facilities are built in compliance with ADA requirements. However, the minimum standards of the ADA fall short of a complete Universal Design framework (Chalfen \& Farb 1996; Mazmdar \& Geis, 2010). Mazmdar \& Geis (2010) note the goal of the ADA is "emancipation and the end of discrimination" (p. 318), and a Universal Design framework helps to shift design into this direction. Therefore, not only will a library facility designed with Principles of Universal Design comply with the ADA, it will exceed the standard and enable all patrons to access information (NC State University, 1997). A universally designed facility features comfort and aesthetic qualities as opposed to an institutional appearance. Lieber (2007) and Schlipf (2011) observe that libraries should be equally comfortable and welcoming to all patrons and that some have accomplished this by shifting policies to allow conversation, food and/or drinks, and providing more study options. This is consistent with Longtin (2014), who points out that providing spaces which are dynamic and varying in use is generally accepted by designers and librarians alike; however, there will always be a need for silent, individual study options. Bodaghi and Zainab (2013) take the patron comfort concept one step further by adding patron security to the list of inclusive qualities. Lieber (2007) observes that libraries, in addition to being comfortable for all users, should look nice to passers-by on the street. These additional Universal Design qualities allow patrons to go beyond simple access to information by allowing them to do so in a facility with desirable aesthetic qualities and consideration of creature comforts.

While libraries have long been lauded for providing accessible facilities (Bonnici, Maatta, \& Wells, 2009), "research on issues of accessibility for library users with disabilities remains scant, albeit growing" (Bonnici, Maatta, Brodsky, \& Steele, 2015, p. 505). Librarians are continuing to further research efforts toward the provision of information access to all users. Bonnici, Maatta, Brodsky, and Steele (2015) point out that the existing structure of training for librarians is to specialize in the provision of services exclusively for disabled users rather than being inclusive of all. This finding is surprising considering the fact the UDL approach permeates almost every learning program in higher education (Burgstahler, 2012; Carabajal, Marshall, \& Atchison, 2017; Curry, 2003; Katz \& Sokal, 2016; Oswald, Nathan Adams, \& Hiles, 2018). Furthermore, Walling (2004) puts forward that librarians have the responsibility of providing inclusive library services when she states, "the ADA... holds information specialists in all types of settings responsible for assuring equal access to all the information they provide" (p.137). The patron is the end-recipient of library services, and Walling (2004) supports Stephanidis et al (1999) when indicating that Universal Design should be incorporated into facilities design and librarian training so that the "emerging information society advances in a manner that ensures nondiscrimination and social and economic inclusion of the broadest possible end-user population, thus posing the requirement for a society caring for all citizens" (p. 26).

The disconnect between the ways librarians are trained to serve the differently-abled student body is evidence that students with disabilities may continue to be marginalized by academic library policy and practices. This marginalization is described by Copeland (2011), who observes this existing social construct is "separatist," or "segregationist," therefore creating a societal attitude that disabled students are the ones that need special accommodation rather than creating a culture of universal acceptance. The social construction of disability also causes those who are already marginalized to have a self-perception of disability. For example, Vaccaro, Kimball, Moore, Newman, and Troiano (2018) explain that "social identities... are influential aspects of self precisely because of the social value (or lack thereof) placed upon them in a particular society" (p. 50). The constructivist perspective is that a person who is "disabled" is

The International Journal of Information, Diversity, \& Inclusion, 4(1), 2020

ISSN 2574-3430, jps.library.utoronto.ca/index.php/ijidi/index

DOI: $10.33137 /$ ijidi.v4i1.32340 
limited only by the entities that surround that individual, such as lack of a ramp for wheelchairs or the staff's willingness to adjust policy and training to be inclusive (Anastasiou \& Kauffman 2011; Bogart, Rottenstein, Lund, \& Bouchard 2017; Copeland, 2011; Walling, 2004). The literature tells us that, although flawed because of the way some librarians are trained to use separatist rather than inclusive instruction, there is a shift in the social construction from that of "disability" and "ADA compliance" toward one of "physically or cognitively varied" and "Universal Design" (Anastasiou \& Kauffman, 2011; Bogart, Rottenstein, Lund, \& Bouchard, 2017; Bonnici, Maatta, \& Wells, 2009; Bonnici, Maatta, Brodsky, \& Steele, 2015; Copeland, 2011; Lieber, 2007; Schlipf, 2011; Vaccaro, Kimball, Moore, Newman, \& Troiano, 2018; Walling, 2004).

\section{Literature Review}

\section{Universal Design and the UAW in Libraries}

Computer technology was an accessible gateway to information for the cognitively and physically varied as early as 1991. The biggest barrier at that time was physical access to the computer (Beecher, 1991; Stephanidis, et al., 1999). Beecher (1991) notes that librarians were among the first to recognize the accessibility built into the "microcomputers" of the late 1980's. Kirkpatrick and Morgan (2001) expand on Beecher's observations by telling us that the computer provides a gateway to barrier-free information access for persons with motor-skill, vision, hearing, and cognitive variation. Whereas in many ways the microcomputer itself was a useful tool for the differently abled in the 1980's (Beecher, 1991), the evolution of the internet in the following decade opened gateways to information for everyone and presented new and unforeseen challenges. For example, Burgstahler, Comden, and Fraser (1997) note that the problems in providing access to the internet for the differently abled populace in 1997 were twofold: access to the computers themselves and access to the tools and electronic resources which comprise the internet. Burgstahler (2015) states, "Designing any product or environment involves the consideration of many factors, including aesthetics, engineering options, environmental issues, industry standards, safety concerns, and cost" (para. 3). This evolution of information delivery leads to a new challenge, which is including technology in library facilities that enables the differently abled to access information in an equitable fashion.

Purchasing assistive and adaptive technology can result in financial challenges for library administrators even though the relative cost to the technology gain has been in decline since 1977 (Greenwood \& Kopecky, 2013, Umbach, 2003). Umbach (2003) recounts how the Calgary Public Library, the Canadian National Institute for the Blind, along with Connect Calgary determined the need for UAW equipment. They first formed a steering committee and performed a study which discovered that one in six citizens had a disability. Conclusions drawn from that study resulted in the purchase of six UAW's for their library, at a cost of $\$ 42,000$. The amount of $\$ 7,000$ per UAW seems expensive when compared to the current purchase power of that same amount in 2019.

One would expect the price of the technology to rise. However, Greenwood and Kopecky (2013) explain the "welfare gain to consumers" (p. 336) and advances in the technology since 2003 can be translated to the current time by use of indexing. In this example, "indexing" means that the improvements in technology outrun the cost of inflation (Greenwood \& Kopecky, 2013). The indexed pricing model of technology demonstrates that the financial burden of providing access to technology has enabled librarians to provide better equipment for the same amount of money over the course of time (Greenwood \& Kopecky, 2013; Nelson, Tanguay, \& Patterson, 1994).

The International Journal of Information, Diversity, \& Inclusion, 4(1), 2020

ISSN 2574-3430, jps.library.utoronto.ca/index.php/ijidi/index

DOI: $10.33137 /$ ijidi.v4i1.32340 
Using the UAW purchase model stated in Umbach (2003), where all components were purchased and implemented at the same time, librarians used Universal Design to create a "one-stop shop" (Wallace, 2007, p. 13) approach toward customer service.

Providing all the tools necessary for any individual to learn and utilize online resources is a critical component of library services (Burgstahler, Comden, \& Fraser, 1997; Burgstahler, 2015; Gossett, Mirza, Barnds, \& Feidt, 2009; Wallace, 2007). Patrons cannot learn that which they cannot access. It is important to recognize that as technology evolves there is a need to update library technology. Wallace (2007) asserts the configuration of the ideal public workstation of today may not be the same as in the future. King (2016) supports this by telling us that sustainability in planning is an "open-ended process" (p. 273). Sustainability, which is a concept closely related to Universal Design, should always be considered when designing any system or facility in order to ensure the user will benefit in the long term (Gossett, Mirza, Barnds, \& Feidt, 2009; Steinfeld, \& Maisel, 2012, p. 38). The UAW is a dynamic set of innovations which incorporate the principles of sustainability and Universal Design, thus penetrating both physical and sociological barriers described by Gossett, Mirza, Barnds, and Feidt (2009), Steinfeld and Maisel (2012), and Robertson (2014). Both physical and sociological barriers stem from the social construction of disability. As a result, building exteriors, interiors, and the technology within are generally designed with accommodation in mind rather than design for all.

Burns (2013) and Moorefield-Lang, Copeland, and Haynes (2016) note that asynchronous instruction in distance education is one more example of Universal Design that increases access to information. A student that uses adaptive technology at home can participate in the learning process as a distance education student; however, providing the UAW in the library ensures that same student has the opportunity to participate as any other student, by ensuring a barrier-free access to information when on-campus (Burns, 2013; Moorefield-Lang, Copeland, \& Haynes, 2016). Moorefield-Lang, Copeland, and Haynes (2016) note that "learning differences represent the largest group of students with disabilities" (p. 30), therefore programs that combine distance learning on-campus facilities that include barrier-free access to information, and a philosophy of universal access are current trends in the modern academic library (Burns, 2013; Curry, 2003). The UAW is a tool which librarians can incorporate into their facility that can help those with disabilities meet their learning needs.

\section{From ADA to a Universal Design Framework}

The words "Universal Design" emerged in accessibility/disability and design literature in the 1990's due to quality determinations by contributors at the Center for Universal Design at North Carolina State University (Catanese, 2012; Story, Mueller, \& Mace, 1998). "Universal Design" was not as frequently used in scholarship until after 1990 when the ADA was passed into law (Bonnici, Maatta, Brodsky, \& Steele, 2015; Gossett, Mirza, Barnds, \& Feidt, 2009). Vavik (2016) explains that teaching the concept of Universal Design "has evolved from applying [Universal Design] principles and guidelines in development of products, services and environments to a closer focus on the design processes itself" (p. 167). This paradigm shift has caused the Universal Design philosophy to be spread to design students. Hidayetoglu and Muezzinoglu (2018) take this one step further by stating that "Universal design education should not only include students, but academics, instructors..." (p. 59) which also includes incorporation of the UDL guidelines promoted by Burgstahler, (2012, 2015); Burns (2013); and Moorefield-Lang, Copeland, and Haynes (2016). UDL guidelines ensure positive student learning outcomes by use of alternative resources and acceptance of alternative learning demonstrations. The guidelines may be used in

The International Journal of Information, Diversity, \& Inclusion, 4(1), 2020 
the traditional classroom, online learning environment, and for students with physical or cognitive variations.

Forrest, Hinchliffe, Arp, and Woodward (2005) note that the way students learn is changing because technology provides an increased number of information delivery methods. Students can watch videos, read articles, complete online tutorials, and collaborate inside both the library and virtual environment. Katz and Sokal (2016) write that UDL pedagogy includes "multiple ways for students to access, process, and represent their learning" (p. 41) such as teacher-led lessons, group discussion, and research using different forms of media. This evolution of ADA standards to Universal Design shows that the government-recognized need for better accessibility led to the more dynamic design framework. Universal Design not only includes the concept of providing access, but also exceeds the government standard in every way by changing the paradigm from "accommodation" to design-for-all by exceeding ADA standards.

Recent literature identifies Universal Design, which includes the UDL pedagogy methods described by Katz and Sokal (2016), as an inclusive process and philosophy (Catanese, 2012; Gossett, Mirza, Barnds, \& Feidt, 2009; Vavik, 2016). As early as 1990, Vanderheiden (1990) pointed out that "consideration of disabilities and functional limitations in mainstream design is definitely feasible from both an economic and a practical standpoint" (p. 392). This implies that Universal Design was recognized as a superior design philosophy as early as 1990 . Stephanidis, et al. (1999) later advocates that the design-for-all nature of Universal Design should apply to all aspects of design, from the chair you sit in to use the computer, to the layout and architecture of the building the computer is in, to the street and mode of transportation the user employs for travel. Hums, Schmidt, Novak, and Wolff (2016), McDonald (2016), Lindegarde (2015), Pionke (2017), and Stephanidis, et al. (1999) all recognize ADA as a minimally adequate standard. However, these authors view Universal Design as a superior design standard for all products and facilities. Stephanidis, et al. (1999) were forward-looking when they stated, "there is also a compelling requirement for speeding up current standardization processes as well as for more intensive international coordination of standards in the long term" (p. 24), in which they were including the development of online applications. Further evidence of this shift away from ADA as the standard to that of Universal Design is evidenced by Vavik (2016), who states, with regard to teaching design students, "although a greater focus now is put on [Universal Design] in the design process, ...the most important change is that the teaching of [Universal Design] has moved from the second year to the first year" (p. 168). In other words, Universal Design is now the foundational standard for good design.

\section{Data in Support of the Literature}

The literature suggests there is a paradigm shift away from looking to minimum ADA requirements toward Universal Design as the standard. Of course, as far as libraries and library instruction are concerned, UDL is included in this shift as well. However, there is a need for data to support that trend and assist library decision-makers with the justification of spending extra money for UAW technology. The financial cost of the technology and librarian attitudes toward Universal Design are factors to be considered in the decision-making process. To determine the proper balance between technology cost and accessibility, more input from librarians is necessary. The shift from ADA as a minimal standard to Universal Design can be gauged, in part, by input from librarians. Data that supports the following of a current trend may provide librarians the leverage they need to promote inclusive access to library materials. This paper provides information which has been gathered from peers that will provide library administrators valuable knowledge to

The International Journal of Information, Diversity, \& Inclusion, 4(1), 2020

ISSN 2574-3430, jps.library.utoronto.ca/index.php/ijidi/index

DOI: $10.33137 /$ ijidi.v4i1.32340 
apply in the decision-making process.

\section{Methodology}

\section{Method}

Survey research methods provide an efficient and practical schema to allow a cross-sectional analysis of how existing library facilities provide computer technology intended to serve an inclusive college student population (Matthews \& Ross, 2010). Data was collected using a distributed survey questionnaire (See Appendix) that was distributed through academic library channels (listservs noted below) in order to explore academic librarian attitudes toward Universal Design, accessibility, and why some academic libraries include a UAW in their facilities while others do not. The survey questionnaire was distributed through networks beyond the knowledge of the researcher, which provides the opportunity to increase the number and diversity of respondents (Creswell, 1994).

The target population for this survey was academic librarians, staff, and library administrators. All collected data were aggregated to provide an optimal amount of information and preserve anonymity. Anonymity was assured in both the solicitation email and the survey instruction page. The questionnaire contained multiple response format questions as well as some open-ended questions in order to provide librarians the opportunity to expand upon their answers. Some of the questions requested demographic data such as number of patrons served, how many students are serviced, and available computers. The questionnaire included why and how questions about how librarians make the decisions regarding the UAW and their library, therefore, the questionnaire utilized the text response in addition to the objective response formatted questions.

\section{Data Collection Tool/Instrument}

The online questionnaire (See Appendix) was distributed via the email listservs: Reference and User Services Association List, rusa-l@lists.ala.org, COLIB-L, lita-l@lists.ala.org, CIRCPLUS, LLAMA BES Facilities Planning Discussion Group, ill-l@oclclists.org, and uniaccess@lists.ala.org. Listserv members were encouraged to distribute the survey to the appropriate persons within their institutions as well as any other channels such as other listservs and social media groups, at their discretion. The sample set of libraries surveyed were asked to provide institutional demographic information (i.e., total number of on-campus students); however, no specific institutional or personal identifying information was requested. A two-month response time was allocated for the survey duration. This timeframe allowed participants sufficient time to access and complete the questionnaire. The survey was delivered in an electronic format using Google Forms. The results from Google Forms were exported into an Excel spreadsheet for analysis. There were 111 responses from academic libraries. Responses from non-academic institutions (15 responses) were discarded.

\section{Survey Questions}

The overall goal of the survey is to gain the perspective of those academic librarians, staff, and library administrators who provide access to information every day. The survey questions (See Appendix) are designed to discover if librarian attitudes are consistent with the literature regarding Universal Design as it relates to technology, and to reveal the existing barriers which

The International Journal of Information, Diversity, \& Inclusion, 4(1), 2020 
prevent the purchase of UAW technology.

\section{Results}

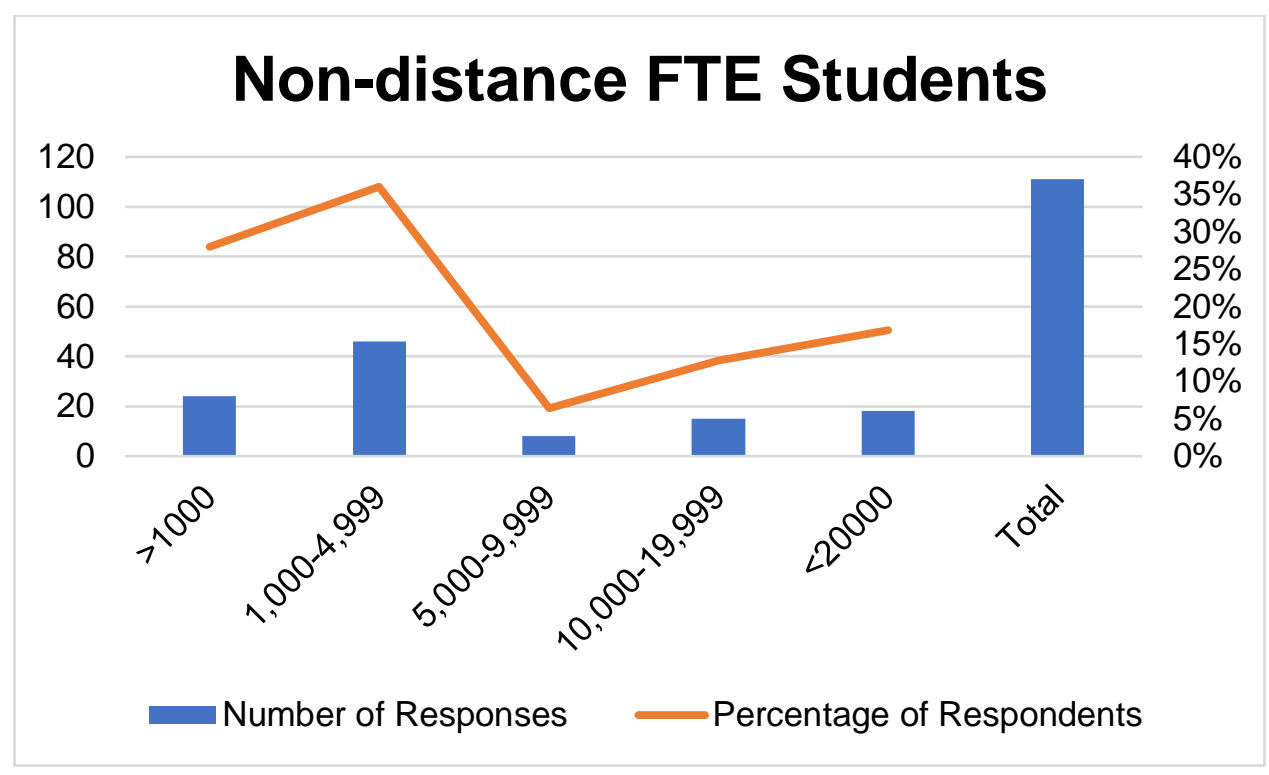

Figure 1. Non-distance FTE Students

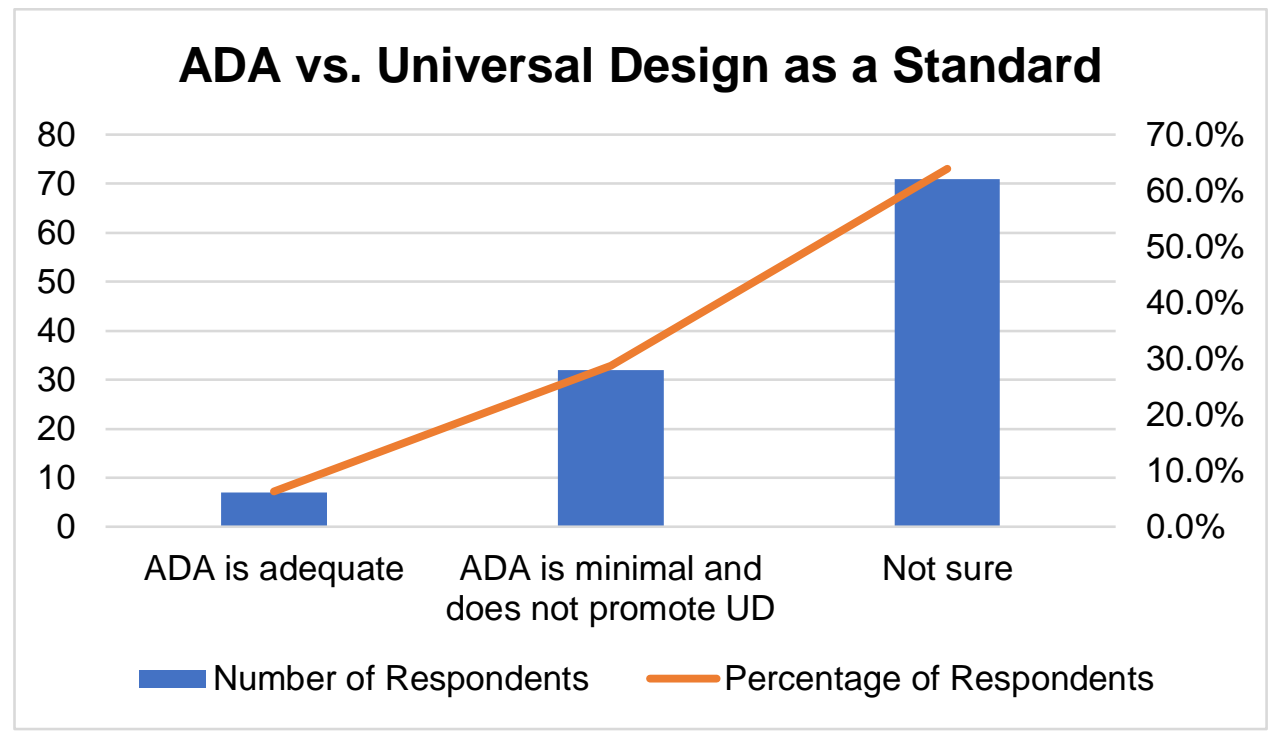

Figure 2. ADA vs. Universal Design as a Standard

The survey resulted in 111 academic library responses. Of these respondents, $28 \%$ serve populations under $1,000,36 \%$ serve $1,000-4,999$ patrons, $6 \%$ serve $5,000-9,999$ patrons, $13 \%$ serve $10,000-19,999$ patrons, and $17 \%$ serve over 20,000 patrons. Given the sample size and number of

The International Journal of Information, Diversity, \& Inclusion, 4(1), 2020

ISSN 2574-3430, jps.library.utoronto.ca/index.php/ijidi/index

DOI: $10.33137 /$ ijidi.v4i1.32340 
patrons served by the respondents, this survey sample is representative of the patronage served by academic librarians, administration, and staff.

\section{Are librarians aware that ADA is a minimal government standard and not a Universal Design and all-inclusive guideline?}

When asked whether they are aware that ADA is a minimal standard rather than an inclusive standard, $64 \%$ of respondents indicate that they are "not sure," whereas $29 \%$ are aware; $6 \%$ of the respondents feel that ADA is an adequate design standard. This empirical data indicate librarians may have limited options outside of ADA standards when making decisions about computer workstation configuration because Universal Design is not regulated by any governing organization. This is consistent with the observations made by Hums, Schmidt, Novak, and Wolff (2016); McDonald (2016); Lindegarde (2015); Pionke (2017); and Stephanidis, et al. (1999), all of whom indicate that Universal Design is superior to ADA as a design standard. Widespread education about Principles of Universal Design is needed among library leaders so that they will understand that Universal Design exceeds ADA standards.

\section{What information do academic library decision-makers need to justify the expense of a UAW?}

Of the 111 total respondents, $64 \%$ indicate that the purchase of technology such as the UAW is reactive, meaning that their library makes technology purchases based on the need of existing patrons whereas the other $36 \%$ indicate a proactive approach. This data demonstrates approximately two-thirds of librarians cite existing patron need as the basis for decision making in this context. Factors indicated in the survey that steer these decisions are lack of responsibility (outside department manages library technology), management of the technology (updating software, maintenance etc.), apathy, and high cost. The survey responses support the literature in that most respondents $(87.3 \%)$ are willing to be proactive and philosophically believe in promoting Universal Design as a best practice (Bonnici, Maatta, Brodsky, \& Steele, 2015; Copeland, 2011, Lieber; 2007, Walling, 2004). The data in Figure 3 shows that finance and apathy are the chief administrative barriers that prevent librarians from taking the proactive approach.

\section{Why should an academic library include a UAW in their facility? Why not? What are the existing barriers?}

Existing major barriers for purchasing the UAW, as indicated by the survey, are financial cost $(84.7 \%)$, administrative red tape $(32.4 \%)$, lack of space $(41.4 \%)$, apathy $(33.3 \%)$, expense not necessary $(25.2 \%)$, adequate existing technology $(26.1 \%)$, lack of supporting literature $(11.7 \%)$, and "other" (11.7\%).

Of the respondents, $11.7 \%$ selected "current literature does not indicate/support a trend," which is consistent with this author's findings that there is a lack of literature about the UAW. One of the goals of this study is to show that libraries which incorporate a Universal Design framework when they select technology such as the UAW can reduce barriers to access (Bonnici, Maatta, Brodsky, \& Steele, 2015; Curry, 2003; Moorefield-Lang, Copeland, \& Haynes, 2016; Vavik, 2016). Participants were able to select multiple responses to this question since there may be more than one barrier. The data indicate that financial cost $(84.7 \%)$ is the number one reason not to purchase or plan a purchase of a UAW.

The International Journal of Information, Diversity, \& Inclusion, 4(1), 2020

ISSN 2574-3430, jps.library.utoronto.ca/index.php/ijidi/index

DOI: $10.33137 /$ ijidi.v4i1.32340 


\section{Are librarians willing to accept including the UAW in their library as a best practice? Is this a trend?}

Results indicate that $78.3 \%$ librarians believe the UAW is a necessary component for their facilities. The results also show there is a desire to add one since $33.3 \%$ of librarians indicate they will consider introducing the idea for consideration and $23.4 \%$ plan to introduce the UAW to their management team. Only $17.1 \%$ of the librarians surveyed indicate they are "Not at all likely" going to consider adding a UAW to their facility, and $82.9 \%$ are positive toward the concept or already own a UAW. There is no benchmark data from years past about how many libraries own a UAW, so this study cannot say there is a current trend toward providing more accessible workstations. This feedback indicates a general agreement amongst librarians that there exists a recognized need for the UAW technology in order to make library environments inclusive. This data, as well as the review of literature, indicate a positive attitude toward the concept as a best practice (Burgstahler, Comden, \& Fraser, 1997; Burgstahler, 2015; Burns, 2013; Curry, 2003; Greenwood \& Kopecky, 2013; Gossett, Mirza, Barnds, \& Feidt 2009; King, 2016; Moorefield-Lang, Copeland, \& Haynes, 2016; Nelson, Tanguay, \& Patterson, 1994; Steinfeld \& Maisel, 2012; Wallace, 2007). The fact that $82.9 \%$ of survey respondents are optimistic about the UAW suggests that there may be a trend toward improving accessibility and inclusive access for patrons, and $24.3 \%$ of the respondents already have a UAW or have a current plan for purchase.

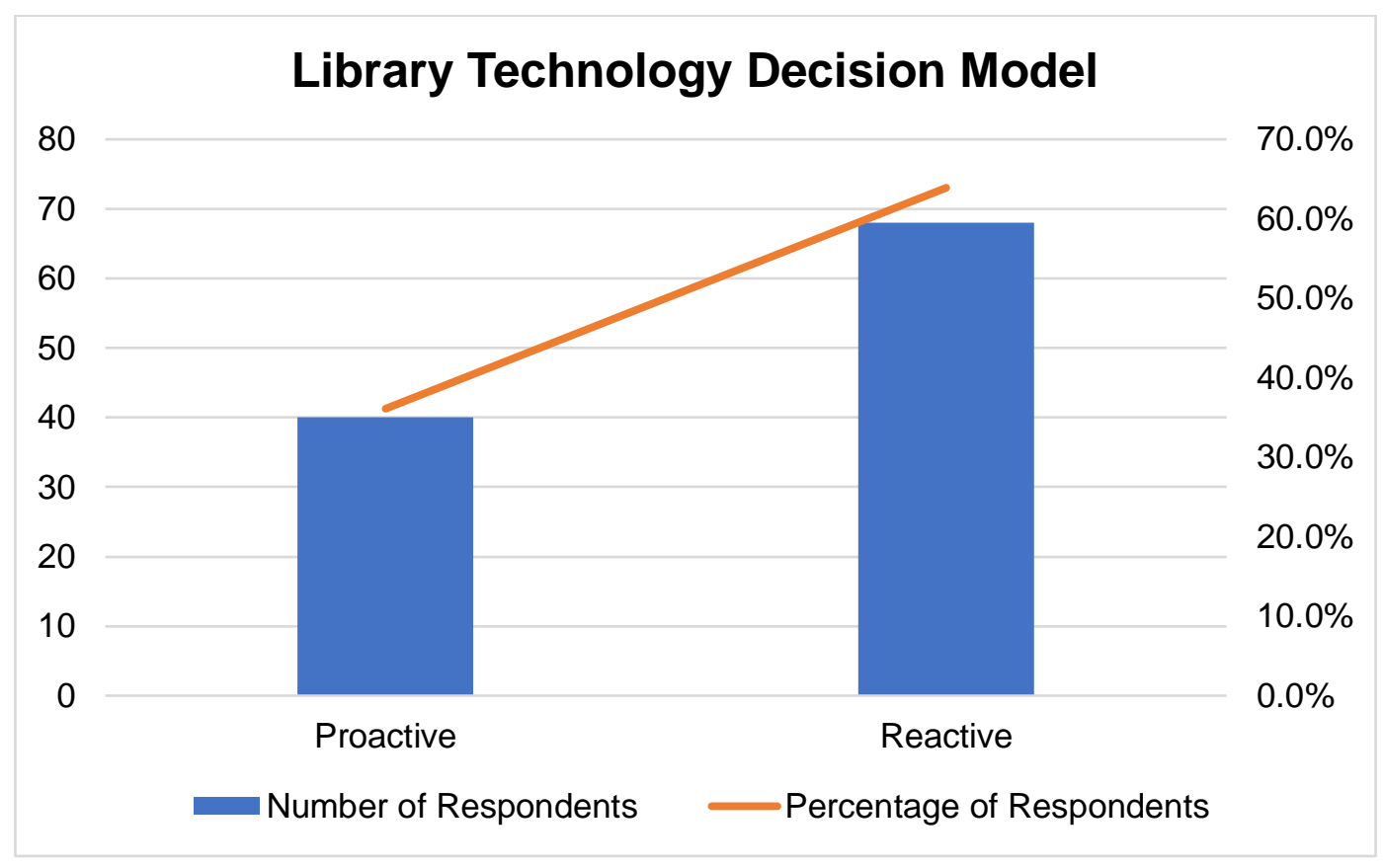

Figure 3. Library Technology Decision Model

The International Journal of Information, Diversity, \& Inclusion, 4(1), 2020

ISSN 2574-3430, jps.library.utoronto.ca/index.php/ijidi/index

DOI: $10.33137 /$ ijidi.v4i1.32340 


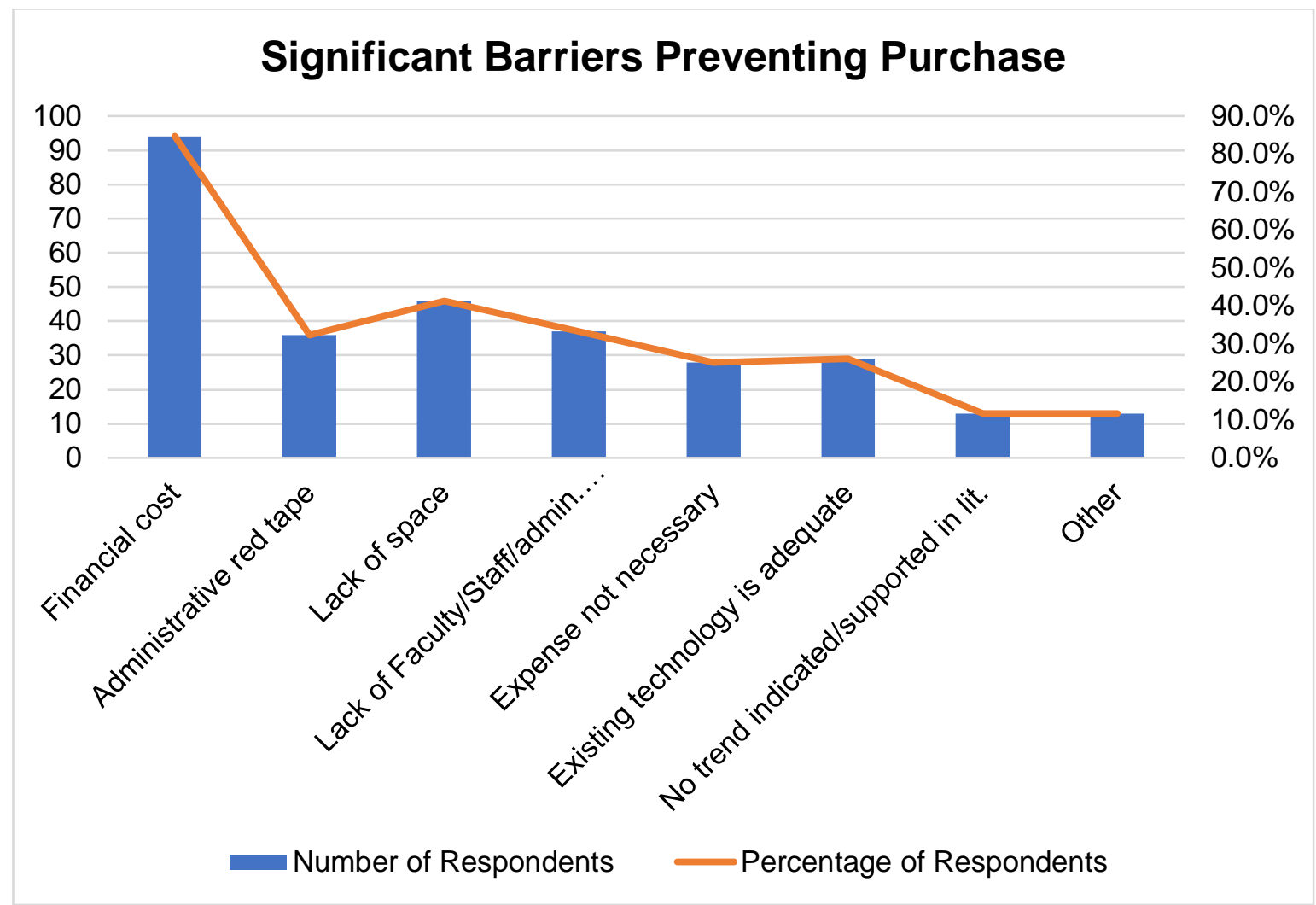

Figure 4. Significant Barriers Preventing Purchase

\section{Consider Adding a UAW to Your Facility?}

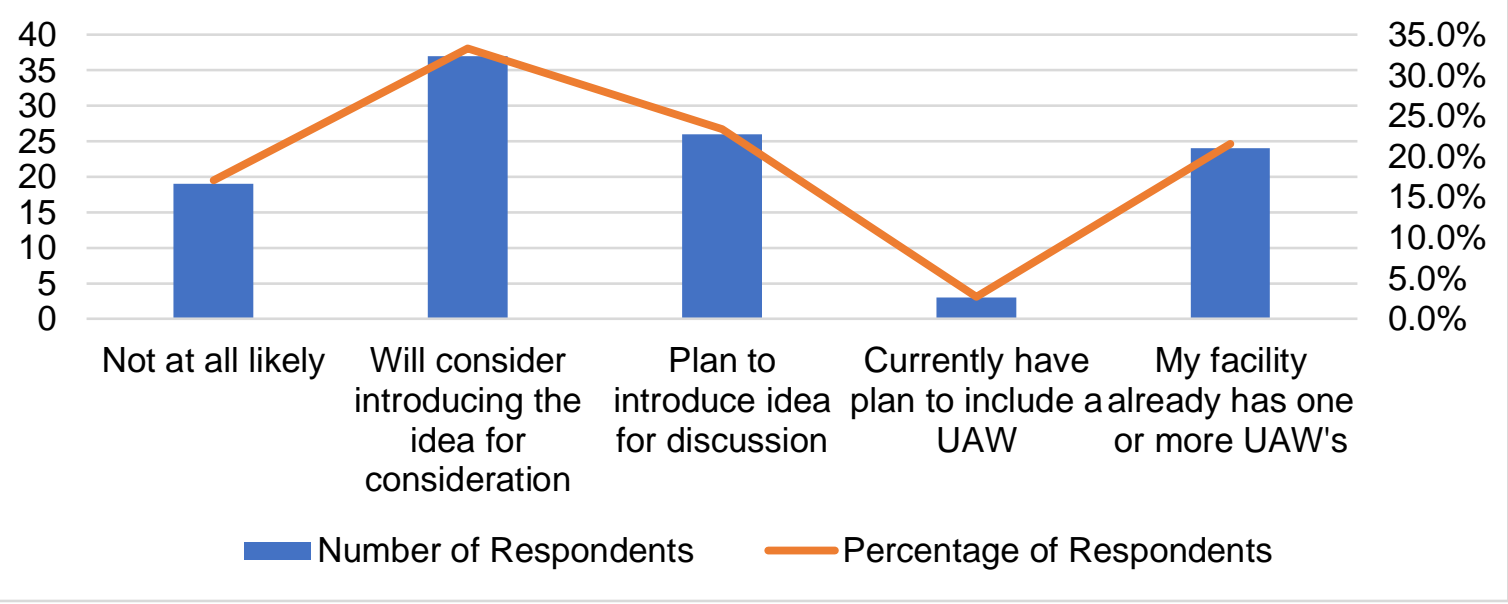

Figure 5. Consider Adding a UAW to Your Facility?

The International Journal of Information, Diversity, \& Inclusion, 4(1), 2020

ISSN 2574-3430, jps.library.utoronto.ca/index.php/ijidi/index 


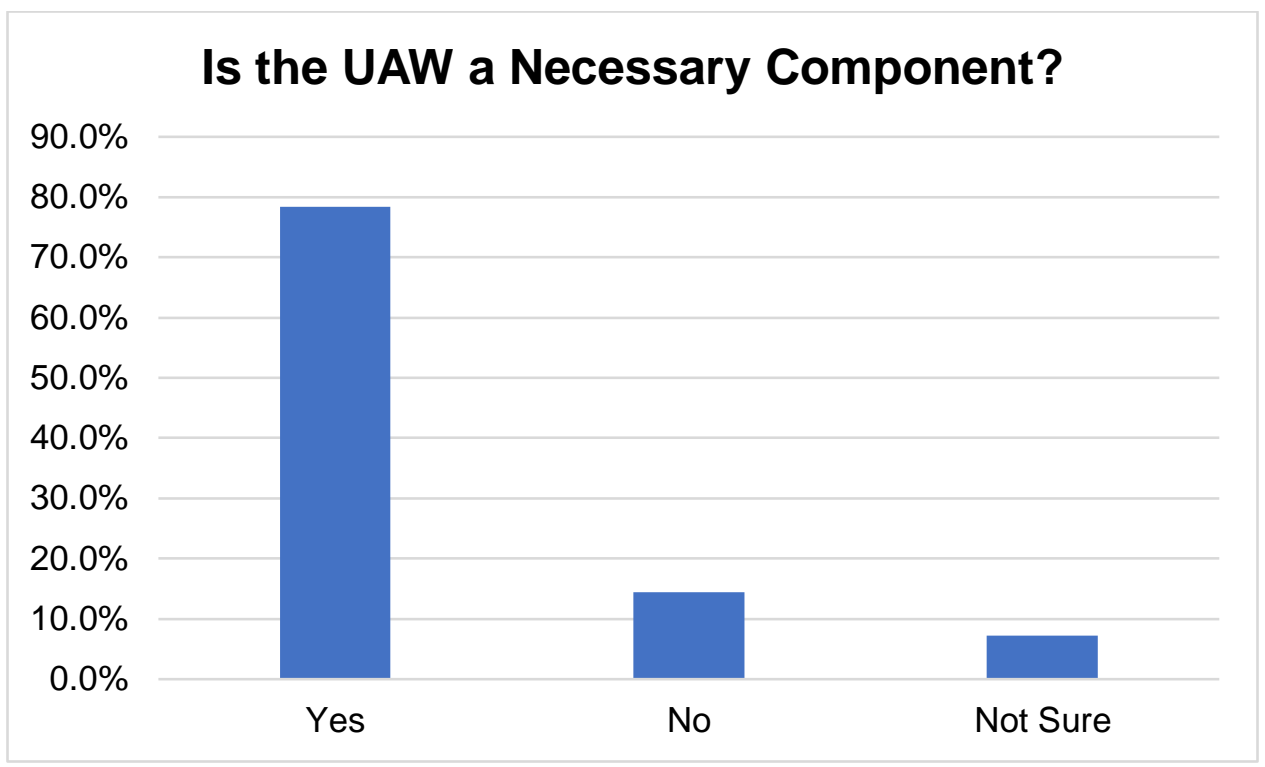

Figure 6. Is the UAW a Necessary Component?

\section{Discussion}

The empirical data demonstrates that many librarians recognize the importance of access to technology in the library, which is consistent with findings from the literature review. Of the librarians surveyed, $39.6 \%$ indicate that they have at least one UAW in their library. Further analysis of the survey data demonstrates most of those $39.6 \%$ of libraries have a configuration with a few elements of the UAW rather than most or all of the components. Therefore, it is reasonable to conclude that the UAW, as described in this study, has not been widely accepted and implemented. The technology patrons use to access information is just as critical as the delivery of information, and this study demonstrates that academic libraries featuring UAW technology have qualities consistent with Universal Design philosophy. This is supported by the fact that $78 \%$ of the respondents feel that the UAW is a necessary component and that $81 \%$ are either willing or have already introduced the UAW into their facilities planning, or already have a UAW. This same survey result is supported by the literature which reveals Universal Design continues to gain acceptance since the technology that students use is part of the overall facility design (Bonnici, Maatta, Brodsky, \& Steele, 2015; Curry, 2003; Moorefield-Lang, Copeland, \& Haynes, 2016; Vavik, 2016).

Of the 111 total responses, only two respondents $(1.8 \%)$ selected "other" as their only choice when asked to indicate the significant barriers that prevent a purchase as illustrated in Figure 4. This means that $98.2 \%$ of the respondents indicate there are multiple barriers preventing them from implementing UAW technology in their libraries. In the "Other comments" open-answer question, one of the two respondents who selected "other" as their only barrier to purchase indicated that the campus office of disability services was surprised when the library reached out to them to discover more about their student population need and seemed unprepared for their questions. This may suggest that some libraries may not receive valuable input from their campus accessibility and disability services offices about student technology need. Even though

The International Journal of Information, Diversity, \& Inclusion, 4(1), 2020

ISSN 2574-3430, jps.library.utoronto.ca/index.php/ijidi/index

DOI: $10.33137 /$ ijidi.v4i1.32340 
finance is the number one administrative barrier, apathy toward accessibility and/or Universal Design plays a strong role in the decision-making process.

The good news for the differently abled university population is that the majority of the librarians surveyed $(82.9 \%)$ feel the addition of the UAW to their libraries is a good idea and is worth exploration. This is despite the extra expense associated with the assistive and adaptive technology. This progressive attitude is consistent with the more recent research which indicates that Universal Design and UDL are trends in academic librarianship (Burgstahler, 2012, 2015; Burns, 2013; Catanese, 2012; Hidayetoglu \& Muezzinoglu, 2018; Hums, Schmidt, Novak, \& Wolff, 2016; McDonald, 2016; Lindegarde, 2015; Moorefield-Lang, Copeland, \& Haynes, 2016; Pionke, 2017; Vavik, 2016). Since the data indicate an overall positive attitude (82.9\%) about the UAW technology, library administrators should be reasonably able to conclude that funds budgeted toward assistive and adaptive technology would be well advised since it promotes equitable access for the differently abled.

\section{Should the UAW Become a Benchmark?}

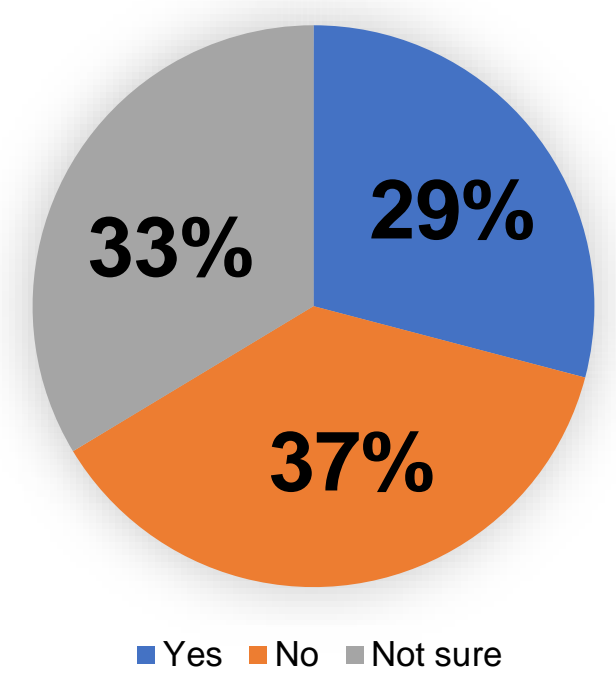

Figure 7. Should the UAW Become a Benchmark?

When asked if the UAW "should be the benchmark by which all library computers should be designed" (See Appendix), the responses of yes, no, and not sure were balanced out approximately in thirds with "No" responses having a slight edge over the "Yes" responses. The $33 \%$ of "Not Sure" replies combined with the 37\% "No" responses suggests that a future followup study which focuses on this as a research question is necessary help us understand where the benchmark for library technology really exists in comparison to the UAW.

One of the goals of this study is to create awareness of the UAW and demonstrate that the social construct of disability is determined, in part, by the facilities which we design. This is consistent

The International Journal of Information, Diversity, \& Inclusion, 4(1), 2020

ISSN 2574-3430, jps.library.utoronto.ca/index.php/ijidi/index

DOI: $10.33137 /$ ijidi.v4i1.32340 
with Copeland (2011), who states "As a social construct, disability is a challenge or a culmination of challenges that doesn't exist until societal factors...create them" (p. 235). It also supports Taylor's IUE, which places the facility in judgement because the information is only as good as the accessibility of that information (Taylor, 1987). In reality, it is not economically feasible for the UAW to be the only configuration of patron workstation in the library. It is reasonable, however, for academic librarians to consider including a representative number of UAW's not to only eliminate barriers to access but enhance accessibility and incorporate Universal Design. The respondents surveyed largely agreed that having a representative number of UAW's in relation to the patron population served would be considered a best practice. This notion is in tune with the argument to progress beyond ADA standards and fully embrace Universal Design as the standard (Pionke, 2017).

\section{Further Study}

Future efforts could utilize a similar survey and focus on responses from libraries outside of North America which would expand contributions to the field of accessibility and disability research. A more international approach could explore how the UAW may be configured to better serve a more culturally diverse population and identify the existing barriers for implementing the UAW in those libraries. The survey results in this project indicate there is a desire for technology such as the UAW. This signals that there is a need for more data and research regarding universal access. Another way to provide this data is to take a closer look at the existing information available on library websites. This would allow researchers to paint a better picture of existing library computer workstation configuration and establish a benchmark by which library administrators can make technology purchasing decisions. A follow up study directed toward a broader library audience would be another method by which to assess the library field for a trend. Continued studies regarding inclusive library environments will also contribute to diversified accessibility studies scholarship.

\section{Conclusion}

In the 1990's, one of the challenges recognized by librarians was the fact that not all users were able to access electronic resources because they were not able to physically access the computer (Beecher, 1991; Stephanidis, et al., 1999). The UAW rectifies the early technological accessibility challenges of the information revolution by allowing all users to access digital information and provide the ability to convert print resources into more accessible digital formats. The evolution of the ideal library workstation from "suit the broadest end-user population" (Stephanidis, et al., 1999, p. 2) in the 1990's to "accommodate all users" (Salmen, 2011, p. 13) in the present day indicates that there may be a positive trend toward acceptance of Universal Design in library technology. This paper helps fill a gap in UAW research by providing data that librarians can use in the decision-making process. Promotion of Universal Design allows the library facility to appeal to all constituents and enables all users to participate in the learning process.

The International Journal of Information, Diversity, \& Inclusion, 4(1), 2020 


\section{Appendix}

\section{Universal Design, Accessibility, and Academic Library Computer Workstations}

\section{Overview}

Greetings and thank you for your participation in this survey. The 18 questions take approximately 10-15 minutes to complete. The purpose of this survey is twofold:

1. Gather information for a study about how librarians and library staff make decisions in regard to accessibility and the computer workstations in academic library facilities.

2. Gauge the perception of accessibility, Universal Design, and inclusive services with respect to library-as-space among academic librarians.

Academic libraries typically feature computer workstations that use the average desktop computer with a standard keyboard and mouse as input devices. A Universal Access Workstation (UAW) allows any person to use the kiosk with all regards to their ability.

\section{Description of the Universal Access Workstation (UAW)}

The UAW is defined as a computer workstation with the following components:

- $\quad$ Screen readers

- Voice capture

- Document reader (converts text to OCR)

- Document magnifiers

- Adaptive internet browser extensions

- Hands-free input device software

- Accessibility functions enabled in operating system
- Large screen monitor

- Document camera

- Noise-cancelling microphone and headphones

- High-visibility keyboard and mouse

- Hands-free input system (pointing device replaces mouse)

- Adaptive trackball mouse

- Switch

- Ergonomic chair

- Footrest

- Wrist wrest

- Push-button adjustable height worktable

Table 1. Description of UAW

\section{Goals, Outcomes, Publishing, and Disclosure}

The goal of the researcher is to share the results from this survey in a peer-reviewed journal article. Results may also be shared in conference presentation. The research team is the only 
entity that will see the individual survey results. No identifying data will be collected, survey results are anonymous, and any published results will be in aggregate form only. Survey responses with identifying information will be omitted and destroyed. Participation in this survey is anonymous and optional. All questions are optional. There are no consequences for refusing to take the survey or opting out during the survey. The researcher conducting this survey is performing research in the spirit of scholarship and is a staff member at the Kimbel Library and Bryan Information Commons, Coastal Carolina University. Participants may discontinue the survey at any time and at their own will. Questions about the survey may be directed to the contact person (below).

\section{Contact Person}

\section{Brady Cross}

Kimbel Library and Bryan Information Commons

Coastal Carolina University

P.O. Box 261954

Conway, SC 29528-6054

bcross@coastal.edu

\section{Instructions}

Please choose the appropriate response(s) indicated for each question. The final question allows participants to share any additional comments or opinions.

Please do not provide any identifying information in this survey. If you have any questions, please direct them to the contact person.

\section{Demographic Questions}

Which one of the following best describes your facility?

(Please choose one response)
a. Academic
b. Public
c. School
d. Special

How many non-distance education student patrons does your facility serve?

(Please choose one response)
a. Under 1,000
b. $1,000-4,999$
c. $5,000-9,999$
d. $10,000-19,999$
e. 20,000 and above

How many computer workstations are available for patron use in your facility?

The International Journal of Information, Diversity, \& Inclusion, 4(1), 2020

ISSN 2574-3430, jps.library.utoronto.ca/index.php/ijidi/index

DOI: $10.33137 /$ ijidi.v4i1.32340 
(Please choose one response)
a. 30 or fewer
b. $31-100$
c. $100-300$
d. $300+$

Which of the following technologies are included with all of the computers in your library? (Select all that apply)

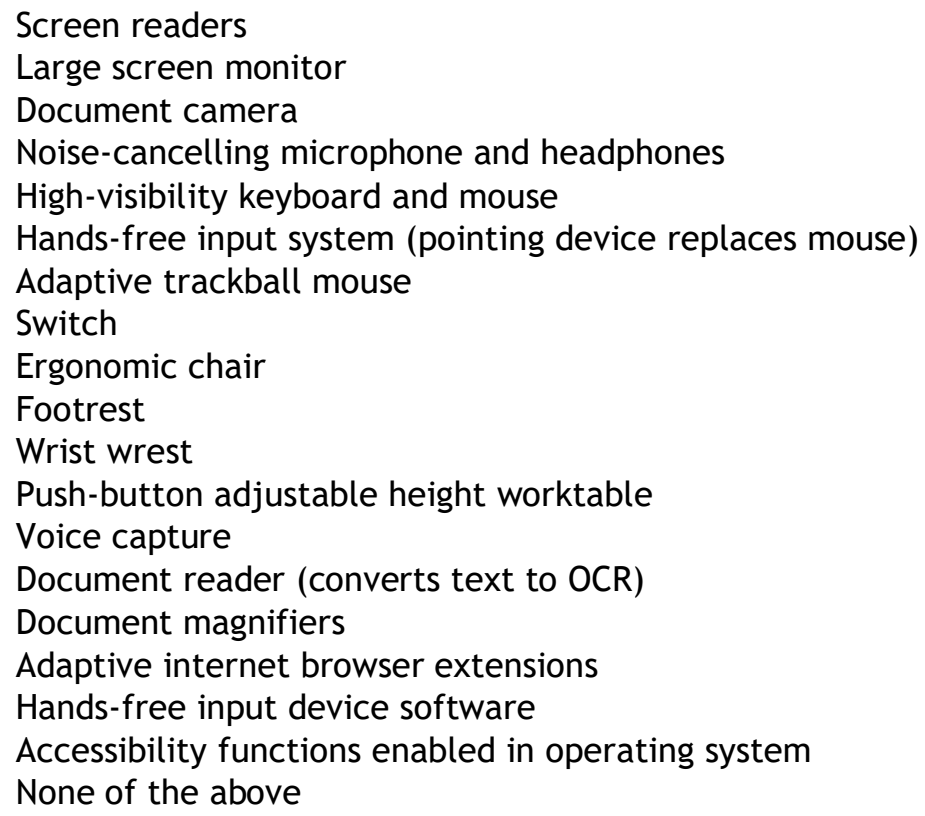

Are patrons permitted to access the Windows and Macintosh operating systems accessibility features on your computers?
a. Yes
b. No
c. Not sure

\section{Universal Access Workstation Questions}

The UAW is defined as a computer workstation with the following components:

Software Hardware and Furniture

\begin{tabular}{|c|c|}
\hline $\begin{array}{ll} & \text { Screen readers } \\
\text { - } & \text { Voice capture } \\
\text { - } & \text { Document reader (converts text to } \\
\text { OCR) }\end{array}$ & $\begin{array}{ll}- & \text { Large screen monitor } \\
\text { - } & \text { Document camera } \\
\text { - } & \text { Noise-cancelling microphone and } \\
& \text { headphones }\end{array}$ \\
\hline
\end{tabular}

The International Journal of Information, Diversity, \& Inclusion, 4(1), 2020

ISSN 2574-3430, jps. library.utoronto.ca/index.php/ijidi/index DOI: $10.33137 /$ ijidi.v4i1.32340 
- Document magnifiers

- Adaptive internet browser extensions

- Hands-free input device software

- Accessibility functions enabled in operating system
- High-visibility keyboard and mouse

- Hands-free input system (pointing device replaces mouse)

- Adaptive trackball mouse

- Switch

- Ergonomic chair

- Footrest

- Wrist wrest

- Push-button adjustable height worktable

Figure 8. Components of a UAW Computer Workstation

How many UAW's (as described above) are in your facility available for patron use? (Please choose one response)
a. 0
b. 1
c. 2
d. 3
e. $4+$

Based on the provided description of a UAW, how likely are you to consider adding a UAW to your facility? (Please choose one response)
a. Not at all likely
b. Will consider introducing the idea for consideration
c. Plan to introduce idea for discussion
d. Currently have plan to include a UAW
e. My facility already has one or more UAW's

Is it your professional opinion that the UAW (as described above) is a necessary component for library facilities? (Please choose one response)
a. Yes
b. No
c. Not sure

If you answered "No" to the above question, please briefly explain why.

Is it your professional opinion the UAW (as described above) should become the standard by which all library computer workstations should be designed? (Please choose one response)
a. Yes
b. No
c. Not sure

The International Journal of Information, Diversity, \& Inclusion, 4(1), 2020

ISSN 2574-3430, jps.library.utoronto.ca/index.php/ijidi/index

DOI: $10.33137 /$ ijidi.v4i1.32340 
Please provide any further thoughts or opinions you would like to share regarding your answer about the UAW as a benchmark.

\section{The UAW in Academic Libraries}

Are you familiar with the 2010 Americans with Disabilities Act and Accessible Design (ADA) guidelines? (Please choose one response)
a. Yes
b. No

Is it your professional opinion that the 2010 Americans with Disabilities Act and Accessible Design (ADA) guidelines are a minimal standard, do not address principles of Universal Design, and therefore do not promote an all-inclusive standard for accessibility?
a. Yes
b. No
c. Not sure

The UAW, as described above, costs approximately $\$ 3,000$ to $\$ 7,000$ depending on vendor pricing and software licensing costs. Do you feel this is a feasible/justifiable technology expense for your facility if funding could be budgeted? (Please choose one response)
a. Yes
b. No
c. Not sure

What are the most significant barriers that may prevent the inclusion of the UAW in your facility? (Please select all relevant barriers)
a. Financial cost
b. Administrative red tape
c. Lack of space
d. Lack of faculty/staff/administrative enthusiasm
e. Expense not necessary
f. Existing technology is adequate
g. Current literature does not indicate/support a trend
h. Other

Does your library make decisions to add technology such as the UAW to promote inclusive services or are such decisions made as a reaction to a demonstrated need? (Please choose one response)

a. Yes, our institution is encouraged to anticipate inclusive need (proactive).

b. No, our institution makes technology purchases based on the need of existing patrons only. We will purchase technology if the need arises in the future (reactive).

Is it your professional opinion that there is a current trend (evolving social construct) to promote Universal Design and accessibility to promote inclusive services and technology in academic libraries? (Please choose one response)

The International Journal of Information, Diversity, \& Inclusion, 4(1), 2020

ISSN 2574-3430, jps.library.utoronto.ca/index.php/ijidi/index

DOI: $10.33137 /$ ijidi.v4i1.32340 

a. Yes
b. No
c. Not sure

Do you think including at least one UAW in every academic library is a good idea and should become a library trend (evolving social construct)? (Please choose one response)
a. Yes
b. No
c. Not sure

Does your college/university provide data (or physical needs) to your library about the differently-able student population on your campus? (Please choose one response)
a. Yes
b. No
c. Not sure

Do you have any other comments, opinions, or other relevant information you would like to share or contribute to this survey? Please refrain from providing any identifying information in your narrative.

\section{Conclusion}

This concludes the survey. Thank you for your participation! Your responses will be used for academic research purposes only. If you have any questions or comments regarding this survey, please direct them to the contact person below.

Contact Person:

Brady Cross

Kimbel Library and Bryan Information Commons

Coastal Carolina University

P.O. Box 261954

Conway, SC 29528-6054

bcross@coastal.edu

\section{References}

Anastasiou, D., \& Kauffman, J. M. (2011). A social constructionist approach to disability: Implications for special education. Exceptional Children, 77(3), 367-384. https://doi.org/10.1177\%2F001440291107700307

Beecher, H. (1991). Public access workstations in the library: New trends. Wilson Library Bulletin, 65(6), 52-54.

Bodaghi, N. \& Zainab, A. (2013), My carrel, my second home: Inclusion and the sense of belonging among visually impaired students in an academic library. Malaysian Journal of Library \& Information Science, 18(2), 39-54.

The International Journal of Information, Diversity, \& Inclusion, 4(1), 2020

ISSN 2574-3430, jps.library.utoronto.ca/index.php/ijidi/index

DOI: $10.33137 /$ ijidi.v4i1.32340 
Bogart, K. R., Rottenstein, A., Lund, E. M., \& Bouchard, L. (2017). Who self-identifies as disabled? An examination of impairment and contextual predictors. Rehabilitation Psychology, 62(4), 553-562. https://doi.org/10.1037/rep0000132

Bonnici, L. J., Maatta, S. L., \& Wells, M. K. (2009). US national accessibility survey: Librarians serving patrons with disabilities. New Library World, 110(11/12), 512-528. https://doi.org/10.1108/03074800911007532

Bonnici, L. J., Maatta, S. L., Brodsky, J., \& Steele, J. E. (2015). Second national accessibility survey: Librarians, patrons, and disabilities. New Library World, 116(9/10), 503-516. https://doi.org/10.1108/NLW-03-2015-0021

Burgstahler, S. (2012). Equal access: Universal design of instruction. Retrieved from https://www.washington.edu/doit/sites/default/files/atoms/files/Equal-AccessUniversal-Design-of-Instruction.pdf

Burgstahler, S. (2015). Universal design of instruction (UDI): Definition, principles, guidelines, and examples. Retrieved from https://www.washington.edu/doit/sites/default /files/atoms/files/UD_Instruction_05_26_15.pdf

Burgstahler, S., Comden, D., \& Fraser, B. (1997). Universal design for universal access: Making the internet more accessible for people with disabilities. Alki, 13(3), 8-9.

Burns, M. (2013). Technology closes the distance: Global solutions show the variety, equity, and accessibility of distance learning options. Journal of Staff Development, 34(3), 2831.

Carabajal, I. G., Marshall, A. M., \& Atchison, C. L. (2017). A synthesis of instructional strategies in geoscience education literature that address barriers to inclusion for students with disabilities. Journal of Geoscience Education, 65(4), 531-541. doi: 10.5408/16-211.1

Catanese, L. (2012). Thomas Lamb, Marc Harrison, Richard Hollerith and the origins of Universal design. Journal of Design History, 25(2), 206-217. https://doi.org/10.1093/jdh/eps013

Chalfen, D. H., \& Farb, S. E. (1996). Universal access and the ADA: A disability access design specification for the new UCLA Library Online Information System. Library Hi Tech, 14(1), 1-56. https://doi.org/10.1108/eb047981

Copeland, C.A. (2011). Library and information center accessibility: The differently-able patron's perspective. Technical Services Quarterly, 28(2), 223-241. https://doi.org/10.1080/07317131.2011.546281

Cresswell, J. W. (1994). Research design: Qualitative \& quantitative approaches. Thousand Oaks, CA: Sage Publications.

Curry, C. (2003). Universal design: Accessibility for all learners. Educational Leadership, 61(2), 55-60.

Forrest, C., Hinchliffe, L. J., Arp, L., \& Woodard, B. S. (2005). Beyond classroom construction

The International Journal of Information, Diversity, \& Inclusion, 4(1), 2020

ISSN 2574-3430, jps.library.utoronto.ca/index.php/ijidi/index

DOI: $10.33137 /$ ijidi.v4i1.32340 
and design. Reference \& User Services Quarterly, 44(4), 296-300.

Gossett, A., Mirza, M., Barnds, A. K., \& Feidt, D. (2009). Beyond access: A case study on the intersection between accessibility, sustainability, and universal design. Disability and rehabilitation: Assistive technology, 4(6): 439-450. https://doi.org/10.3109/17483100903100301

Greenwood, J. \& Kopecky, K. A. (2013). Measuring the welfare gain from personal computers. Economic Inquiry, 51(1), 336-347. https://doi.org/10.1111/j.1465-7295.2011.00447.x

Hidayetoglu, M. L., Muezzinoglu, K. M. (2018). User-involved universal design experience in the space, product, and service development process. Iconarp International Journal of Architecture and Planning, 6(0), 41-62. https://doi.org/10.15320/iconarp.2018.48

Hums, M. A., Schmidt, S. H., Novak, A., \& Wolff, E. A. (2016). Universal design: Moving the Americans With Disabilities Act from access to inclusion. Journal of Legal Aspects of Sport, 26(1), 36-51. https://doi.org/10.1123/jlas.2015-0011

Katz, J., \& Sokal, L. (2016). Universal design for learning as a bridge to inclusion: A qualitative report of student voices. International Journal of Whole Schooling, 12(2), 36.

King, J. G. (2016). Extended and experimenting: Library learning commons service strategy and sustainability. Library Management, 37(4), 265-274. https://doi.org/10.1108/LM-042016-0028

Kirkpatrick, C., \& Morgan, C. (2001). How we renovated our library, physically and electronically, for handicapped patrons. Computers in Libraries, 21(9), 24-29.

Lieber, C. (2007). Be a guest: A French look on American libraries. Library Administration \& Management, 21(4), 178-180.

Lindegarde, S. (2015). ADA compliance becoming more universal. PM Engineer, 21(5), 10.

Longtin, S. E. (2014). Using the college infrastructure to support students on the autism spectrum. Journal of Postsecondary Education and Disability, 27(1), 63-72.

Matthews, B. \& Ross, L. (2010). Research methods: A practical guide for the social sciences. Harlow, England: Pearson Education Limited.

Mazmdar, S. \& Geis, G. (2010). Achieving accessibility through the Americans with Disabilities Act: An examination of court decisions. Journal of Architectural and Planning Research, 24(4), 301-304.

McDonald, J. (2016). Why ADA is not your enemy. CSP, 27(14), 26.

Moorefield-Lang, H. M., Copeland, C. A., \& Haynes, A. (2016). Accessing abilities: Creating innovative accessible online learning environments and putting quality into practice. Education for Information, 32(1), 27-33. http://dx.doi.org/10.3233/EFI-150966

NC State University, Center for Universal Design, College of Design (1997). The principles of

The International Journal of Information, Diversity, \& Inclusion, 4(1), 2020

ISSN 2574-3430, jps.library.utoronto.ca/index.php/ijidi/index

DOI: $10.33137 /$ ijidi.v4i1.32340 
universal design. Version 2.0. NC State University. Retrieved from https://www.ncsu.edu/ncsu/design/cud/pubs_p/docs/poster.pdf

Nelson, R. A., Tanguay, T. L., \& Patterson, C. D. (1994). A quality-adjusted price index for personal computers. Journal of Business \& Economic Statistics, 12(1), 23-31.

Oswald, G. R., Nathan Adams, R. D., \& Hiles, J. A. (2018). Universal design for learning in rehabilitation education: Meeting the needs for equal access to electronic course resources and online learning. Journal of Applied Rehabilitation Counseling, 49(1), 1922. doi: 10.1891/0047-2220.49.1.19

Pionke, J. J. (2017). Beyond ADA compliance: The library as a place for all. Urban Library Journal, 23(1), 1-17.

Robertson, M. (2014). Sustainability principles and practice. New York, NY: Routledge.

Salmen, J. S. (2011). Universal design for academic facilities. New Directions for Student Services, 2011(134), 13-20. https://doi.org/10.1002/ss.20113

Schlipf, F. (2011). The dark side of library architecture: The persistence of dysfunctional designs. Library Trends, 60(1), 227-255. https://doi.org/10.1353/lib.2011.0034

Story, M. F., Mueller, J. L., \& Mace, R. L. (1998). The Universal design file: Designing for people of all ages and abilities. NC State University: The Center for Universal Design. Retrieved from https://projects.ncsu.edu/design/cud/pubs_p/pudfiletoc.htm

Steinfeld, E. S., \& Maisel, L. J. (2012). Public accommodations. In Universal design: Creating inclusive environments. Hoboken, NJ: John Wiley \& Sons.

Stephanidis, C., Salvendy, G., Akoumianakis, D., Arnold, A., Bevan, N., Dardailler, D., et al. (1999). Toward an information society for all: $\mathrm{HCl}$ challenges and R\&D recommendations. International Journal of Human-Computer Interaction 11, 1-28. https://doi.org/10.1207/s15327590ijhc1101_1

Taylor, R.S. (1987). On the study of information use environments. ASIS '86. Proceedings of the 4Ninth ASIS Annual Meeting. Volume 23. Chicago, Illinois, September 28-October 2, 1986, 23, 331-334.

Umbach, J. M. (2003). Access for all. Feliciter, 49(2), 58.

Vaccaro, A., Kimball, E. W., Moore, A., Newman, B. M., \& Troiano, P. F. (2018). Narrating the self: A grounded theory model of emerging purpose for college students with disabilities. Journal of College Student Development, 59(1), 37-54. http://dx.doi.org/10.1353/csd.2018.0003

Vanderheiden, G. C. (1990). Thirty-something million: should they be exceptions? Human Factors: The Journal of the Human Factors and Ergonomics Society, 32(4), 383-396. https://doi.org/10.1177/001872089003200402

Vavik, T. (2016). Facilitating the concept of Universal Design among design students: Changes

The International Journal of Information, Diversity, \& Inclusion, 4(1), 2020

ISSN 2574-3430, jps.library.utoronto.ca/index.php/ijidi/index

DOI: $10.33137 /$ ijidi.v4i1.32340 
in teaching in the last decade. Studies in Health Technology \& Informatics, 229, 167168.

Wallace, A. (2007). Rethinking the public workstation. Reference \& User Services Quarterly, 46(4), 12-17.

Walling, L.L. (2004), Educating students to serve information seekers with disabilities. Journal of Education for Library and Information Science, 45(2), 137-148.

http://dx.doi.org/10.2307/40323900

Brady C. Cross (brady.cross@outlook.com) is the Digital Initiatives Librarian at Tri-County Technical College in Pendleton, SC. He completed his Master of Library and Information Science (MLIS) degree from the University of South Carolina in August 2017. He made Accessibility and Universal Design the central focus of his research throughout his MLIS program. Having lived with a mild hearing impairment all his life, he understands some of the challenges experienced by those with disabilities and wishes to ensure library patrons always have equitable access to information. 